\title{
Membrane-based clarification of banana juice: pre-treatment effect on the flux behaviour, fouling mechanism and juice quality attributes
}

\author{
${ }^{1}$ Yee, W.P., ${ }^{1,2, *}$ Nor, M.Z.M., ${ }^{1,2}$ Basri, M.S.M. and ${ }^{3}$ Roslan, J. \\ ${ }^{1}$ Department of Process and Food Engineering, Faculty of Engineering, Universiti Putra Malaysia, 43400 \\ UPM Serdang, Selangor, Malaysia \\ ${ }^{2}$ Laboratory of Halal Science Research, Halal Products Research Institute, Universiti Putra Malaysia, \\ Putra Infoport, 43400 UPM Serdang Selangor, Malaysia \\ ${ }^{3}$ Faculty of Food Science and Nutrition, Universiti Malaysia Sabah, Jalan UMS, 88400 Kota Kinabalu, \\ Sabah, Malaysia
}

\section{Article history: \\ Received: 16 May 2020 \\ Received in revised form: 21 \\ July 2020 \\ Accepted: 17 October 2020 \\ Available Online: 3 January 2021}

\section{Keywords:}

Banana,

Clarification,

Fruit Juice,

Membrane process,

Pectinase,

Ultrafiltration

\section{DOI:}

https://doi.org/10.26656/fr.2017.5(S1).046

\begin{abstract}
The processing of banana into clarified juice provides an alternative in the beverages market, but further exploration of the related processing is required. Hence, this study investigated the pre-treatment effect during the membrane-based process on the flux behaviour, fouling mechanism and banana juice quality attributes. Observation on juice viscosity was done after the crude banana juice was pre-treated with $0.1-0.5 \%$ pectinase. Both pectinase-treated and untreated banana juices were then subjected to an ultrafiltration process using a $100 \mathrm{kDa}$ dead-end polyethersulfone membrane to clarify the juice. This study found a $50-55 \%$ viscosity reduction of the banana juice after the pre-treatment, with no significant difference in terms of the pectinase concentrations. Pre-treatment of the banana juice prior to ultrafiltration also have improved the permeate flux by $65.5 \%$ compared to the untreated sample. Based on the fitting of several fouling models, cake layer formation on the entire surface of the membrane was identified as the main cause of the membrane fouling and flux deterioration. The ultrafiltration process has significantly improved the juice turbidity, total soluble solid and colour, at a stable $\mathrm{pH}$, indicating the success of the clarification process.
\end{abstract}

\section{Introduction}

Banana is a herbaceous plant of the family Musaceae, which is a type of tropical fruit that is widely planted in Asia and South America. Its fruits contain various essential nutrients such as sodium, potassium, magnesium, Vitamin A and C (Sagu, Nso, Karmaka et al., 2014). Banana is well-known as the world's leading crop due to its nutrition aspects and economic value. In Malaysia, banana is the second-largest cultivated fruit crop after oil palm (Chai et al., 2018). The production of banana had highly contributed to the economic gain to numerous countries as it has been the most consumed fruit in the world and also considered as an important worldwide staple food. Banana fruit is mostly consumed fresh or can be processed into various types of food products e.g. puree, chips, jam, desserts, wine, vinegar, and as functional food ingredients (Sodchit et al., 2014). One other potential processing opportunity of this fruit is by converting it into fruit juice, as this is an excellent alternative to overcome the surplus, overripe and rejected banana fruit issues. The banana juice can potentially offer great benefits such as boosting the energy level in our body since it contains high sugar. Besides, it also a good source of dietary fibre to increase our digestion system and prevent constipation while providing other nutrients including vitamins and minerals.

Normally, clarification of fruit juices is a standard practice by the industry to increase consumer acceptance due to better appearance and colour properties. Besides, it is also performed for improvement in safety, quality and nutritional attributes of the product with fundamental consideration on process cost minimization (Conidi et al., 2020). One of the most accepted juice clarification methods is the membrane filtration technology. Membrane filtration is a method to separate particles in liquid solutions or gas mixtures through a semi-porous material. It is a pressure-driven process which can be classified into several categories: microfiltration (MF), ultrafiltration (UF), nanofiltration (NF) and reverse osmosis (RO), depending to the pore sizes of the 
membrane (Nor et al., 2017). This technology requires fewer chemical additives to remove impurities and is able to perform isothermally at low temperatures. Thus, reducing the energy consumption compared to the traditional methods such as flocculants and coagulation process (Omar et al., 2020). Besides, this technology can retain the original nutritional value and quality of the fruit juice (Conidi et al., 2020). Moreover, the membrane -based operation does not require any phase changes. These features had contributed essential factors to produce natural fresh taste fruit juice.

By considering the advantages offers by the membrane filtration process, its adoption in the clarification process of fruit juice is a wise choice. However, this technology has a limitation in terms of membrane blockage issue - known as "fouling", which is partly affected by the compositions of the fruit juice, particularly with the presence of pectin. The existence of pectin in fruit juices including banana juice can promote the formation of a gel layer on the membrane surface during the filtration process, resulting in a flux deterioration. Thus, a pre-treatment is required to remove the pectin content in the fruit juice. This may involve a treatment using a pectinase enzyme to hydrolyse the pectin, which will result in the reduction of the juice viscosity and subsequently facilitate the filtration process.

Previous studies have reported the successes of using the membrane filtration in the clarification of various fruit juices including apple, black currant, orange, kiwi, lemon, pineapple, pomegranate, watermelon, raspberry as well as banana (Conidi et al., 2020). Besides, a pretreatment with pectolytic enzymes such as pectinase is normally performed to reduce the formation a secondary dynamic layer on the surface of the membrane to reduce the risk of membrane fouling (Mohammadi et al., 2020). Efforts in clarifying banana juice using membrane filtration have been reported by Sims and Bates (1994) and Sims et al. (1994), however some additives some like potassium sorbate and ascorbic acid have been used. Sagu, Nso, Karmaka et al. (2014) and Sagu, Karmaka, Nso et al. (2014) have studied the effect on banana juice shelf life through hollow fibres ultrafiltration-based clarification with the incorporation of a low-temperature pectinase treatment, but the impact of the enzymatic pretreatment on the fouling mechanism during the UF process required further investigation. Thus, this study aims to explore the application of the membrane-based process using ultrafiltration (UF) for banana juice clarification by observing the effect of pre-treatment on the permeate flux behaviour, fouling mechanism, and juice quality attributes.

\section{Materials and methods}

\subsection{Banana juice preparation}

Fresh banana fruits of the Cavendish variety were purchased from a local store in Serdang, Selangor, Malaysia. The bananas were manually peeled with a knife and cut into pieces and blended with an equal weight of distilled water for $1 \mathrm{~min}$. The extract was filtered through a cheesecloth prior to centrifugation at $9000 \mathrm{rpm}$ for $15 \mathrm{mins}$ at room temperature. The obtained supernatant, known as the raw banana juice, was used as a feed for the enzymatic pre-treatment and ultrafiltration (UF) process.

\subsection{Enzymatic pre-treatment}

Sample of $500 \mathrm{~mL}$ raw banana juice was subjected to an enzymatic pre-treatment prior to UF process using pectinase (EC 3.2.1.15) from Aspergillus niger with an activity of 3800 unit $/ \mathrm{ml}$ (Sigma-Aldrich, Merck, St. Louis, Missouri, USA) at different enzyme concentrations i.e. $0.1,0.2,0.3,0.4$ and $0.5 \%$ (by the sample volume). A control sample without any enzymatic treatment was also prepared. All enzymatictreated samples were incubated in a water bath (903, Protech Electronic, Malaysia) at $33^{\circ} \mathrm{C}$ for 108 mins (Sagu, Karmaka, Nso et al., 2014). After the enzymatic treatment, the enzyme in the samples was deactivated by heating the samples at $95^{\circ} \mathrm{C}$ for 5 mins (Sagu, Karmaka, Nso et al., 2014). The samples were then centrifuged (5804R, Eppendorf, Germany) at $9000 \mathrm{rpm}$ for $10 \mathrm{mins}$ to separate the suspended solids. The obtained supernatants were subjected to viscosity measurement or UF process.

\subsection{UF experimental set-up and procedures}

A laboratory-scale membrane stirred cell unit (Amicon ${ }^{\circledR}$, Millipore, USA) was used in this study. For the suitability of the process, a polyethersulfone deadend disc with $100 \mathrm{kDa}$ molecular weight cut-off (MWCO) and $0.0032 \mathrm{~m}^{2}$ active area was selected based on the recommendation by the previous reports (CastroMuñoz et al., 2018; Omar et al., 2020). In all experimental runs, the UF was performed with the initial capacity of $100 \mathrm{ml}$ of juice, and at the operating pressure of 2 bar. The UF process stopped when it reached $80 \%$ of permeate recovery (Omar et al., 2020). The flux performance was measured by observing the permeate flux $(J)$ as described in Equation (1):

$$
J=\frac{1}{\mathrm{~A}_{\mathrm{m}}} \times \frac{\Delta \mathrm{W}}{\Delta t}
$$

Where $A_{m}$ is the effective membrane area $\left(\mathrm{m}^{2}\right)$ and $(\Delta \mathrm{W} /$ $\Delta t)$ is the permeate weight $\Delta \mathrm{W}$ collected over time $\Delta t$ $\left(\right.$ kg. $\left.h^{-1}\right)$. 


\subsection{Fouling mechanism determination}

Fouling models of three types were used to understand the fouling mechanism during the process by considering the relationship between the variation of permeate flux and filtration time (Cassano et al., 2008). The characteristic equation proposed is described in Equation (2):

$$
I=\frac{J_{o}}{1+J_{o} K t}
$$

Where $J_{o}$ is the initial permeate flux while $K$ and $t$ are a coefficient and time, respectively. Based on Equation (2), different equations were derived for different fouling mechanisms as summarized in Table 1 . In order to determine the primary fouling mechanism during the UF process in this study, the experimental data were fitted by each model using a linear regression function in Microsoft Excel 2018 (USA) where the highest coefficient of determination $\left(\mathrm{R}^{2}\right)$ was identified.

\subsection{Viscosity, $\mathrm{pH}$ and total soluble solid measurement}

The apparent viscosity of the banana juice samples was measured using a controlled stress/controlled strain (CS/CR) rheometer (MCR 301; Anton Paar GmbH, Graz, Austria) with a double gap cylinder geometry (DG.26.7/Q1; Anton Paar $\mathrm{GmbH}$ ) at the increment of shear rate from 0 to $500 \mathrm{~s}^{-1}$ (Nor et al., 2018). The $\mathrm{pH}$ of the juices was determined using a $\mathrm{pH}$ meter (Con 700, Oakton, USA) calibrated with buffer solutions of $\mathrm{pH} 4$ and 7. Total Soluble Solids (TSS) was determined using a digital refractometer (RP-101, Atago, Tokyo, Japan) in terms of ${ }^{\circ}$ Brix.

\subsection{Turbidity and colour measurement}

The turbidity of the samples was determined using a turbidity meter (TN-100, Eutech Instrument, Singapore) and was reported in Nephelometric Turbidity Units (NTU). It was calibrated with patron solutions of 0-1000 NTU. The colour properties were determined using a colourimeter (CS-2000, Konica Minolta, USA) and were expressed in terms of $\mathrm{L}^{*}$ (lightness index), a* (rednessgreenness) and $b^{*}$ (yellowness-blueness).

\subsection{Total phenolic content determination}

A Folin-Ciocalteau assay was used to determine the total phenolic content (TPC). The reduction of the FolinCiocalteau reagent by the phenolic compounds in the juice was measured using a UV-VIS spectrophotometer (Ultraspec 3100 Pro, Amersham Pharmacia Biotech, UK) at $765 \mathrm{~nm}$ by referring to a gallic acid standard curve.

\subsection{Statistical analysis}

All tests were performed at least in duplicate. The obtained data were subjected to one-way analysis of variance (ANOVA) using Statistical Analysis System (SAS) software (Version 9.2, SAS Institute, USA). The $\mathrm{t}$ -test was used to compare the mean values at a significance level of $\alpha=0.05$.

\section{Results and discussion}

\subsection{Effect of enzymatic pre-treatment on the juice} viscosity

Figure 1 shows the apparent viscosity of untreated and enzymatic-treated juice at different pectinase concentrations of $0.1-0.5 \%$. The juice viscosity reduced significantly by $50-55 \%$ after being treated with pectinase compared to the untreated sample. This finding indicates that pectin is one of the major polysaccharide components present in the banana juice. Since polysaccharide, especially pectin existence resulted in a high juice viscosity, pectinase enzyme has been widely used in the fruit juice industry to hydrolyse the galacturonan backbone of pectic polysaccharides of plant tissues, resulting in a lower juice viscosity (Nor et al., 2018). This is needed in the juice processing as low viscosity will facilitate the subsequent juice processing, including during the clarification process.

However, no significant difference in the apparent viscosity at different pectinase percentages of the banana juice is found in Figure 1. This can be linked to the amount of pectin present in the juice. The juice might contain pectin, but merely in a minimal amount, that $0.1 \%$ pectinase is deemed sufficient to degrade it. Further study might be required to see the impact of using pectinase at a concentration below $0.1 \%$, however, for this study, a $0.1 \%$ pectinase has been selected to treat the banana juice for the subsequent UF processing.

Table 1. Different fouling mechanism causing the flux decay during the UF process

\begin{tabular}{clcc}
\hline Fouling model & \multicolumn{1}{c}{ General description } & Final equation & Equation number \\
\hline I & Cake formation fouling due to the characteristics of the membrane. & $\frac{1}{J}=\frac{1}{J_{o}}+K t$ & 3 \\
II & $\begin{array}{l}\text { Cake formation fouling due to the entire membrane surface is } \\
\text { covered by a layer of particles. }\end{array}$ & $\frac{1}{J^{2}}=\frac{1}{J_{o}{ }^{2}}+K t$ \\
III & $\begin{array}{l}\text { Pore blocking fouling due to some fractions of pores are } \\
\text { completely blocked by particles. }\end{array}$ & $\ln J=\ln J_{o}+K t$ \\
\hline
\end{tabular}




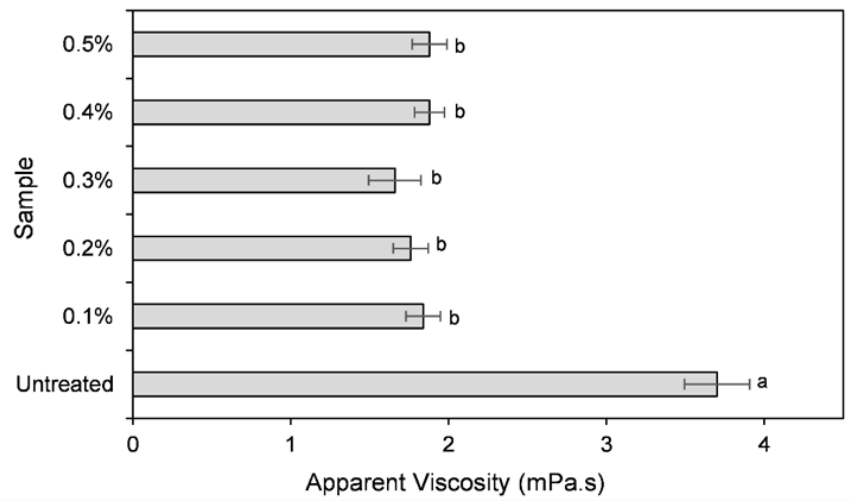

Figure 1. Apparent viscosity of untreated and enzymatictreated banana juice at different pectinase concentrations (different letters are significantly different at $\mathrm{p}<0.05$ ).

\subsection{Evaluation of the flux behaviour and fouling formation during UF process}

Figure 2 exhibits the permeate flux profiles $(J)$ of the untreated and pectinase-treated banana juice during the UF process at 2.0 bar. In general, the flux of both samples shows a declining trend at a different time interval $(t)$. The declination of the flux in Figure 2 has three phases of drastic reduction, minor reduction, and steady-state, which can be related to the fouling phenomenon taking place on the surface membrane during the filtration process (Omar et al., 2020). The drastic declination is due to the blocking of the membrane pores during the first few mins of operation. It was then followed by an occurrence of a gel polarisation by the suspended solids, which were rejected by the membrane and gradually led to the formation of deposition of these solids on the membrane surface (Castro-Muñoz et al., 2018). These depositions create higher resistance for the other solutes to pass through the membrane and subsequently, causing the permeate flux to decrease.

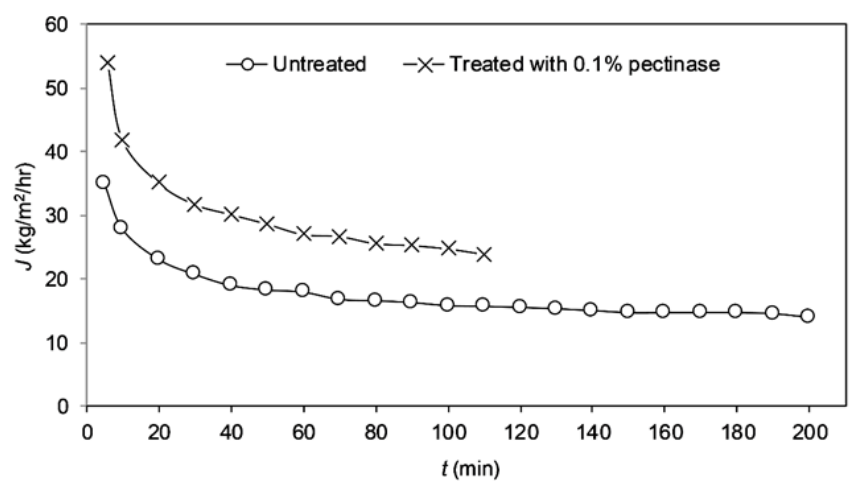

Figure 2. Permeate flux profiles of untreated and enzymatictreated banana juice during UF process.

Based on Figure 2, it is apparent that the pectinasetreated juice has a higher steady-state permeate flux rate $\left(24 \mathrm{~kg} / \mathrm{m}^{2} / \mathrm{hr}\right)$ compared to the untreated juice $(14.5 \mathrm{~kg} /$ $\mathrm{m}^{2} / \mathrm{hr}$ ). This indicates the enzymatic pre-treatment has facilitated the improvement of the permeate flux by
$65.5 \%$. The time to filter $100 \mathrm{~mL}$ of the untreated juice was almost double (200 mins) in comparison with the pectinase-treated sample (110 mins). Generally, the pressure-driven membrane process is dependent on the physicochemical composition of the extracts. As for the banana juice in this study, pectin is believed to be the main composition to cause fouling during the UF process. Pectin can form a highly viscous gel-type layer on the membrane surface, in which under high shearing conditions, its hydrophobicity characteristic can increase due to the interaction with other macromolecules like proteins (Nor et al., 2018). Hence, the membrane process efficiency will deteriorate due to this additional resistance and hindrance.

The treatment of the banana juice with pectinase prior to the UF will facilitate the filtration process since the juice viscosity has been reduced and less fouling formation on the membrane surface. Many similar findings have been reported previously such as for the application of pineapple, cherry, blackcurrant, passion fruit, apple, and lemon juices (Urosevic et al., 2017).

As the membrane fouling might limit the successful application of the membrane filtration in the industry, details study should be performed to understand the fouling mechanism during the process. Figure 3 (a) to (f) exhibit the linear fitting of experimental data of untreated and pectinase-treated samples to different fouling models during the UF process. Three models were compared, in particular, model I, model II, and model III - all of which were reported in the literature, which considers a relationship between the variation of permeate flux and filtration time (Cassano et al., 2008). The highest $\mathrm{R}^{2}$ of each sample signifies which model that best represents the experimental data. Based on Figure 3 (a) to (f), the best model to represent the flux profiles for both the untreated and pectinase-treated banana juice is model II. Model II describes that the main cause of membrane fouling is due to the cake formation as the entire membrane surface is covered by a layer of particles. The cake formation on the membrane surface during the banana juice filtration is expected since fruit juice contains many natural macromolecules, including polysaccharides, suspended solids, colloidal particles, and proteins (Omar et al., 2020). Cassano et al. (2008) has also reported the same fouling mechanism while filtering kiwi juice to recover its bioactive compounds.

This type of fouling mechanism was still dominant during the UF process in this study, although the juice has been priory pre-treated with the pectinase enzyme. However, the cake layer is assumed to be more compact and has a higher thickness in the UF process of the untreated sample, causing higher resistance to the permeate flux compared to the pectinase-treated juice 

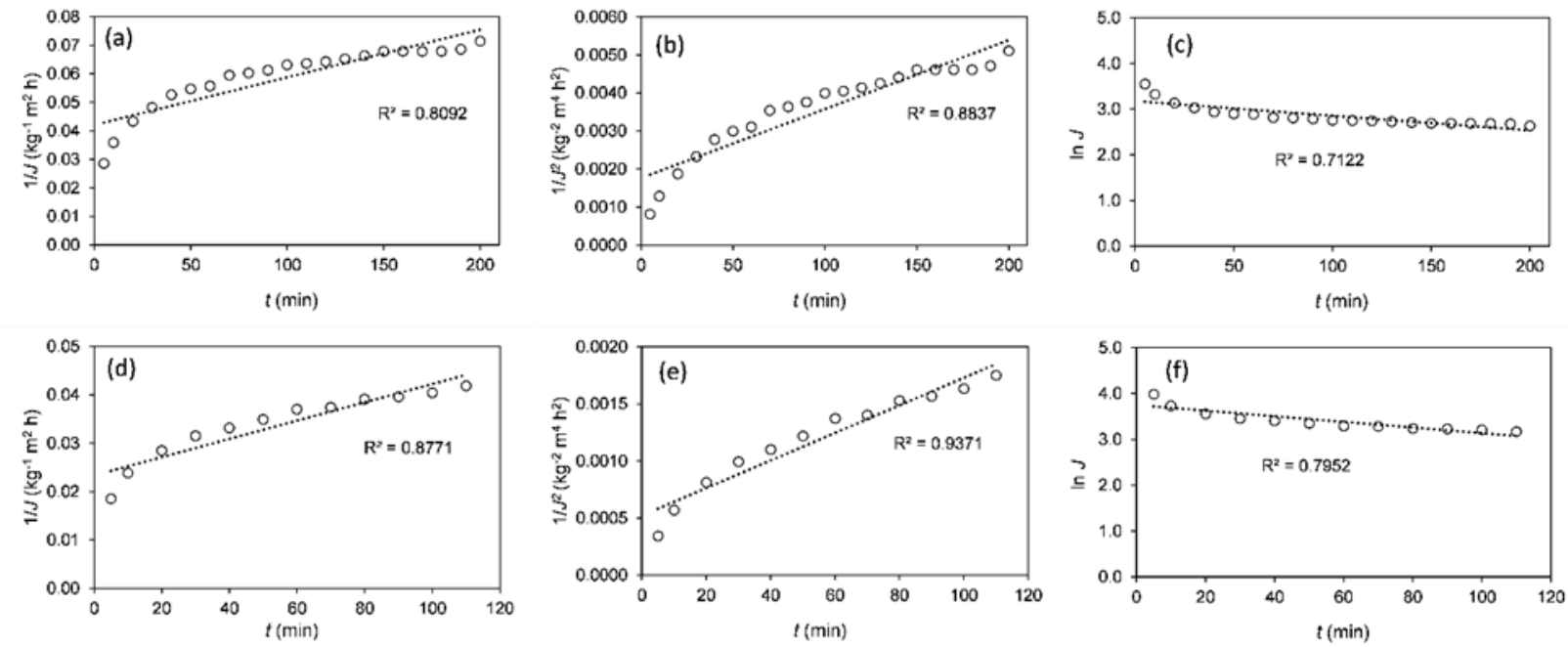

Figure 3. Experimental data fitting on different fouling models of the untreated sample (a) model I; (b) model II; and (c) model III; and the pectinase-treated sample (d) model I; (e) model II; and (f) model III

(Figure 2). Nevertheless, the cake formation is considered reversible fouling, hence by adopting suitable cleaning measures, the membrane permeability is expected to be recovered (Sagu, Karmaka, Nso et al., 2014).

\subsection{Evaluation of the clarified guava juice quality}

\subsection{1 $\mathrm{pH}$ and TSS}

Table 2 shows the $\mathrm{pH}$ and total soluble solids (TSS) properties of untreated and pectinase-treated banana juice after the filtration process. No significant changes were noticed on the $\mathrm{pH}$ of the juice after completing the process (Table 2). The finding indicates that the juice $\mathrm{pH}$ was stable throughout the UF, which is needed for an efficient process. One possible cause of this finding is the removal of bacteria and the acidic substances produced by bacteria in the permeate which leads to no change of the $\mathrm{pH}$ (Akhtar et al., 2020). This is in agreement with other previous studies (Castro-Muñoz et al., 2018; Omar et al., 2020).

Table 2. Analysis of $\mathrm{pH}$ and TSS of the untreated and pectinase-treated banana juice subjected to UF process

\begin{tabular}{llcc}
\hline \multicolumn{1}{c}{ Treatment } & Sample & $\mathrm{pH}$ & $\begin{array}{c}\text { Total Soluble } \\
\left.\text { Solids ( }{ }^{\circ} \text { Brix }\right)\end{array}$ \\
\hline \multirow{2}{*}{ Untreated } & Feed & $4.91 \pm 0.02^{\mathrm{a}}$ & $12.2 \pm 1.3^{\mathrm{a}}$ \\
& Filtrate & $4.90 \pm 0.01^{\mathrm{a}}$ & $7.1 \pm 0.3^{\mathrm{b}}$ \\
& Retentate & $4.88 \pm 0.06^{\mathrm{a}}$ & $13.2 \pm 1.0^{\mathrm{a}}$ \\
\hline \multirow{2}{*}{ Treated with $0.1 \%$} & Feed & $4.85 \pm 0.02^{\mathrm{a}}$ & $10.2 \pm 2.2^{\mathrm{a}}$ \\
pectinase & Filtrate & $4.86 \pm 0.01^{\mathrm{a}}$ & $6.3 \pm 0.1^{\mathrm{b}}$ \\
& Retentate & $4.90 \pm 0.01^{\mathrm{a}}$ & $10.9 \pm 0.2^{\mathrm{a}}$ \\
\hline
\end{tabular}

Means $( \pm$ SD) with the different letters are significantly different at $\mathrm{p}<0.05$ for each column of the section

The UF process, however, caused some reductions in TSS value in the filtrate of the untreated and pectinasetreated banana juice, as shown in Table 2, with a reduction of 42 and $35 \%$ TSS, respectively. The finding reflects the retention of some of the soluble solids in the juice by the membrane. These might include some components of TSS such as sugars, mineral salts, and some organic acids (Castro-Muñoz et al., 2018). Although these components are considerably smaller than the MWCO of the membrane $(100 \mathrm{kDa})$, it is expected that their permeation was partly hindered due to some blockage of the membrane pores (Sagu, Nso, Karmaka et al., 2014).

\subsubsection{Turbidity and colour}

The turbidity of untreated and pectinase-treated banana juice subjected to the UF process is presented in Figure 4. Overall, the UF process has successfully reduced the turbidity value of the juice drastically with a reduction of 96 and $98 \%$ for untreated and pectinasetreated samples, respectively. Since turbidity is linked with the existence of fibres, suspended solids, high molecular weight carbohydrates, and TSS (CastroMuñoz et al., 2018), the membrane used in this study has successfully rejected these components, as proven by the high turbidity in the retentate stream. Membrane technology has been widely used for clarification of different fruit juices, including pineapple, blackberry, melon, and apple for consumer acceptance (Bhattacharjee et al., 2017). In this study, the turbidity of the filtered pectinase-treated banana juice was almost gone with only $0.8 \mathrm{NTU}$ after the UF process. The pretreatment of the juice with pectinase prior to the UF process is believed to further enhance the juice clarity since most of the pectic substances that can potentially cause cloudiness to the juice have been hydrolysed. This was indicated by the lower initial turbidity of the pectinase-treated feed juice (79.67 NTU) compared to the untreated juice (100.85 NTU).

The reduction in the turbidity of banana juice resulting in a visually clean product. Clear fruit juice can be more attractive and pleasant for human consumption 
(Omar et al., 2020). Furthermore, the removal of turbidity denoted a remarkable change that able to be observed on the colour properties of the banana juice. Figure 5 shows the colour changes of the pectinasetreated banana juice before and after the UF process. The membrane-based clarification process has resulted in the clarified banana juice to be "limpid" and "glassy" in comparison with the raw, feed, and retentate juice. These changes can be further evidenced by the lightness/ darkness $\left(\mathrm{L}^{*}\right)$, greenness/redness $\left(\mathrm{a}^{*}\right)$ and yellowness/ blueness $\left(b^{*}\right)$ values of the samples in Table 3 .

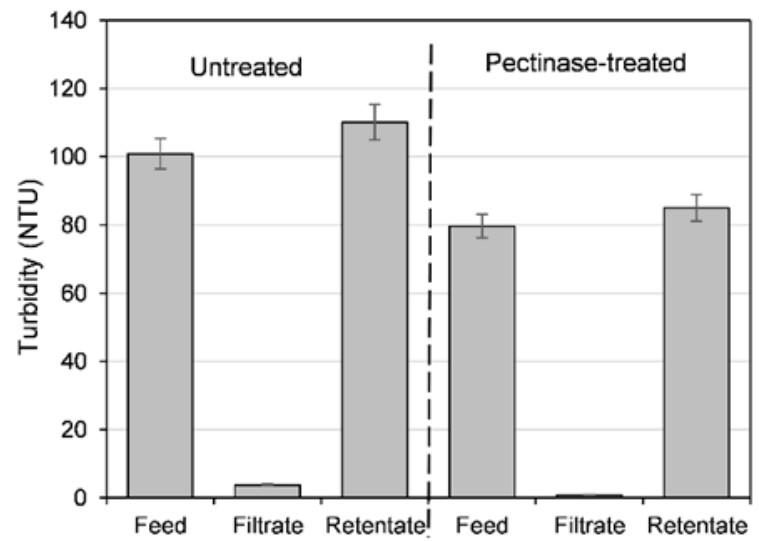

Figure 4. Turbidity of untreated and pectinase-treated banana juice subjected to UF process.

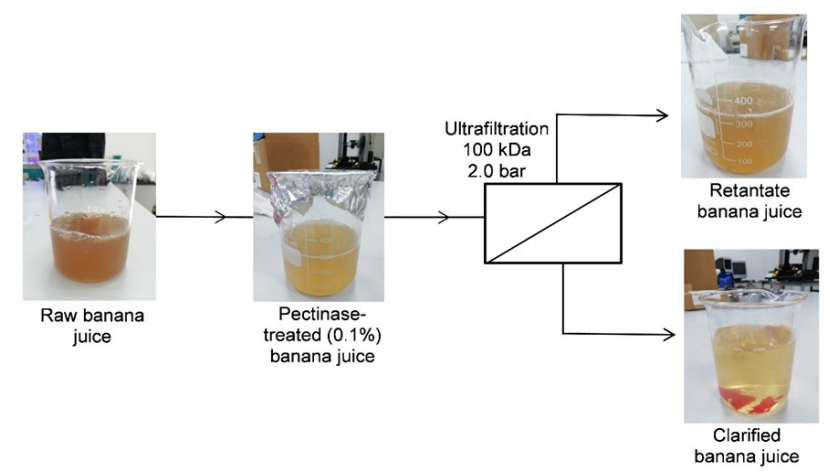

Figure 5. Process illustration of membrane-based clarification of banana juice.

Table 3. Analysis of colour properties of the untreated and pectinase-treated banana juice subjected to UF process.

\begin{tabular}{|c|c|c|c|c|}
\hline \multirow{2}{*}{ Treatment } & \multirow{2}{*}{ Sample } & \multicolumn{3}{|c|}{ Colour } \\
\hline & & $\mathrm{L}$ & $\mathrm{a}^{*}$ & $\mathrm{~b}^{*}$ \\
\hline \multirow{3}{*}{ Untreated } & Feed & $30.7 \pm 1.5^{\mathrm{a}}$ & $3.0 \pm 2.0^{\mathrm{a}}$ & $19.1 \pm 1.2^{\mathrm{a}}$ \\
\hline & Filtrate & $34.9 \pm 1.2^{\mathrm{b}}$ & $5.2 \pm 0.5^{\mathrm{b}}$ & $14.3 \pm 2.0^{\mathrm{b}}$ \\
\hline & Retentate & $29.8 \pm 3.3^{\mathrm{a}}$ & $3.0 \pm 0.6^{\mathrm{a}}$ & $23.1 \pm 1.6^{\mathrm{c}}$ \\
\hline \multirow{3}{*}{$\begin{array}{l}\text { Treated with } \\
0.1 \% \text { pectinase }\end{array}$} & Feed & $31.4 \pm 1.3^{\mathrm{a}}$ & $3.9 \pm 1.3^{\mathrm{a}}$ & $18.4 \pm 3.2^{\mathrm{a}}$ \\
\hline & Filtrate & $36.6 \pm 0.6^{b}$ & $6.3 \pm 0.7^{\mathrm{b}}$ & $13.0 \pm 0.3^{b}$ \\
\hline & Retentate & $30.1 \pm 1.3^{\mathrm{a}}$ & $3.9 \pm 2.3^{\mathrm{a}}$ & $21.7 \pm 2.1^{\mathrm{c}}$ \\
\hline
\end{tabular}

Means $( \pm \mathrm{SD})$ with the different letters are significantly different at $\mathrm{p}<0.05$ for each column of the section.

From Table 3, the filtered banana juice has a significantly higher $\mathrm{L}^{*}$ value compared to the feed and retentate streams after the UF process, reflecting the process has managed to produce a juice that was more translucent and clearer. Meanwhile, the banana juice filtered through the UF process also has some degree of redness and yellowness, indicating from the higher $\mathrm{a}^{*}$ and a lower $b^{*}$ value of the filtrate compared to the feed and retentate. In comparison to the untreated juice, the pectinase-treated banana juice samples (feed, filtrate, and retentate) have a higher $\mathrm{L}^{*}$ and $\mathrm{a}^{*}$ value with a lower $\mathrm{b}^{*}$ value in general, since the pectin has been degraded prior to the UF process.

\subsubsection{Total phenolic content (TPC)}

Figure 6 shows the total phenolic content (TPC) each stream after the UF process of the untreated and pectinase-treated banana juice. The UF process has affected the TPC in the juice by a 22 and $21.7 \%$ reduction in the filtered untreated and pectinase-treated banana juice, respectively, compared to the feed. Although the nutritional value degradation of the juice is not a desired outcome of the process, the same finding has been reported by other studies as well - by associating it due to oxidation and interaction with other compounds rejected by the membranes (Castro-Muñoz et al., 2018; Omar et al., 2020). A 55\% reduction of phenolic contents was reported during the clarification of banana juice using a hollow fibre membrane (Sagu, Nso, Karmaka et al., 2014). Nevertheless, although reductions in polyphenols might compromise the nutrition quality of the extract, it also signifies that the astringency of the clarified juice has also been reduced (Omar et al., 2020). Hence, the reduction of TPC might be a good alternative from the sensory perspective.

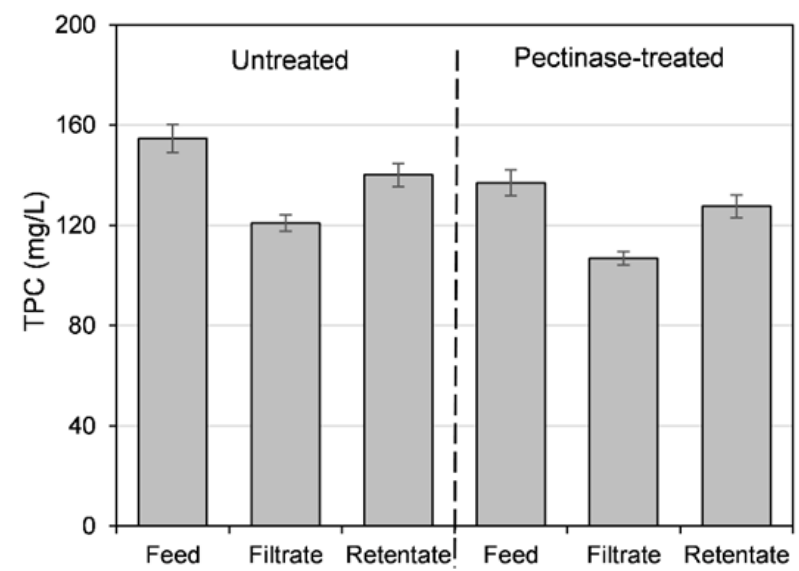

Figure 6. TPC of untreated and pectinase-treated banana juice subjected to UF process.

\section{Conclusion}

A pre-treatment with pectinase has resulted in a significant apparent viscosity reduction of the banana juice, which led to a better filtration performance during the UF process. A $0.1 \%$ pectinase was deemed sufficient 
for the pre-treatment of the banana juice as no significant difference in the apparent viscosity at different pectinase percentages. The pectinase-treated juice has a higher permeate flux rate compared to the untreated juice during the UF process, in which the filtration time can be reduced by half. Meanwhile, cake formation has been identified as the leading cause of membrane fouling. A combination of pectinase pre-treatment and UF process has successfully produced a filtered banana juice that was low in TSS and turbidity, at a maintained $\mathrm{pH}$ and enhanced colour properties. Some TPC reduction has also been identified due to oxidation and solute interactions, but it might be good from a sensory perspective.

\section{Acknowledgement}

The authors would like to thank the Ministry of Higher Education Malaysia for sponsoring this work under UPM Putra Grant: GP/2018/9656000.

\section{References}

Akhtar, A., Senthilmurugan, S., Mohanty, K., Sundar, R., Unnikrishnan, R. and Hareesh, U.S. (2020). Sugarcane juice clarification by lanthanum phosphate nanofibril coated ceramic ultrafiltration membrane: PPO removal in absence of lime pretreatment, fouling and cleaning studies. Separation and Purification Technology, 249, 117157. https:// doi.org/10.1016/j.seppur.2020.117157

Bhattacharjee, C., Saxena, V.K. and Dutta, S. (2017). Fruit juice processing using membrane technology: A review. Innovative Food Science and Emerging Technologies, 43, 136-153. https://doi.org/10.1016/ j.ifset.2017.08.002

Cassano, A., Donato, L., Conidi, C. and Drioli, E. (2008). Recovery of bioactive compounds in kiwifruit juice by ultrafiltration. Innovative Food Science and Emerging Technologies, 9(4), 556-562. https://doi.org/10.1016/j.ifset.2008.03.004

Castro-Muñoz, R., Fíla, V., Barragán-Huerta, B.E., Yáñez-Fernández, J., Piña-Rosas, J.A. and ArboledaMejía, J. (2018). Processing of Xoconostle fruit (Opuntia joconostle) juice for improving its commercialization using membrane filtration. Journal of Food Processing and Preservation, 42(1), 1-9. https://doi.org/10.1111/jfpp.13394

Chai, S.Y., Abbasiliasi, S., Lee, C.K., Ibrahim, T.A.T., Kadkhodaei, S., Mohamed, M.S., Hashim, R. and Tan, J.S. (2018). Extraction of fresh banana waste juice as non-cellulosic and non-food renewable feedstock for direct lipase production. Renewable Energy, 126, 431-436. https://doi.org/10.1016/ j.renene.2018.03.050

Conidi, C., Drioli, E. and Cassano, A. (2018). Membrane -based agro-food production processes for polyphenol separation, purification and concentration. Current Opinion in Food Science, 23, 149-164. https://doi.org/10.1016/j.cofs.2017.10.009

Mohammadi, M., Mokarram, R.R., Shahvalizadeh, R., Sarabandi, K., Lim, L.T. and Hamishehkar, H. (2020). Immobilization and stabilization of pectinase on an activated montmorillonite support and its application in pineapple juice clarification. Food Bioscience, 36, 100625. https://doi.org/10.1016/ j.fbio.2020.100625

Nor, M.Z.M., Ramchandran, L., Duke, M. and Vasiljevic, T. (2017). Application of membranebased technology for purification of bromelain. International Food Research Journal, 24(4), 16851696.

Nor, M.Z.M., Ramchandran, L., Duke, M. and Vasiljevic, T. (2018). Performance of a Two-Stage Membrane System for Bromelain Separation from Pineapple Waste Mixture as Impacted by Enzymatic Pretreatment and Diafiltration. Food Technology and Biotechnogy, 56(2), 218-227. https:// doi.org/10.17113/ftb.56.02.18.5478

Omar, J.M., Nor, M.Z.M., Basri, M.S.M. and Che Pa, N.F. (2020). Clarification of guava juice by an ultrafiltration process: analysis on the operating pressure, membrane fouling and juice qualities. Food Research, 4(S1), 85-92. https://doi.org/10.26656/ fr.2017.4(s1).s30

Sagu, S.T., Nso, E.J., Karmakar, S. and De, S. (2014). Optimisation of low temperature extraction of banana juice using commercial pectinase. Food Chemistry, 151, 182-190. https://doi.org/10.1016/ j.foodchem.2013.11.031

Sagu, S.T., Karmakar, S., Nso, E.J., Kapseu, C. and De, S. (2014). Ultrafiltration of banana (Musa acuminata) juice using hollow fibres for enhanced shelf life. Food and Bioprocess Technology, 7(9), 2711-2722. https://doi.org/10.1007/s11947-014-1309 $-7$

Sims, C.A. and Bates, R.P. (1994). Challenges to processing tropical fruit juices: banana as an example. In Proceedings of the Florida State Horticultural Society, 107, 315-319

Sims, C.A., Bates, R.P. and Arreola, A.G. (1994). Colour, polyphenoloxidase, and sensory changes in banana juice as affected by heat and ultrafiltration. Journal of Food Quality, 17(5), 371-379.

Sodchit, C., Tochampa, W., Kongbangkerd, T. and Singanusong, R. (2013). Effect of banana peel 
cellulose as a dietary fibre supplement on baking and sensory qualities of butter cake. Songklanakarin Journal of Science and Technology, 35(6), 641-646.

Urošević, T., Povrenović, D., Vukosavljević, P., Urošević, I. and Stevanović, S. (2017). Recent developments in microfiltration and ultrafiltration of fruit juices. Food and Bioproducts Processing, 106, 147-161. https://doi.org/10.1016/j.fbp.2017.09.009 